\title{
Study on Application of Phytoremediation Technology in Management and Remediation of Contaminated Soils
}

\author{
Kokyo Oh, Tiehua Cao, Tao Li, and Hongyan Cheng
}

\begin{abstract}
Phytoremediation is an emerging and eco-friendly green engineering technology that utilizes the natural properties of plants to remediate contaminated soils, water and sediments. Soil contamination by various inorganic and organic compounds has been a worldwide concern, and phytoremediation has benn received increasing attention for remediation of these contaminants. However, the practical application of phytoremediation has been limited because of its low remediation efficiency. This paper addresses phytoremediation on its characteristics, research status, with emphasis on description of its practical application in management and remediation of soil contaminated sites.
\end{abstract}

Index Terms-Soil contamination, soil resources, management, phytoremediation, practical application.

\section{INTRODUCTION}

Soil is the fundamental foundation of our agricultural resources, food security, global economy and environmental quality [1]. With the development of urbanization and industrialization, soils have become increasingly polluted by heavy metals and organic pollutants, which threaten ecosystems, surface and ground waters, food safety and human health [2]. Hence, there is a great need to develop effective technologies for sustainable management and remediation of the contaminated soils.

There are conventionally physicochemical soil remediation engineering techniques such as soil washing, incineration, solidification, vapor extraction, thermal desorption, and disposal as waste, anyway, these methods usually cause secondary air or groundwater pollution, and/or destroy the plant productive properties of soils. Moreover, they are usually extremely high in cost, limiting their extensive application particularly in developing countries and for remediation of agricultural soils [1].

Phytoremediation has been increasingly received attentions over the recent decades, as an emerging and eco-friendly approach that utilizes the natural properties of plants to remediate contaminated soils [3]. By growing plants in the contaminated sites, contaminants in soils will be removed, immobilized, or degraded, and the cost is much less

Manuscript received June 13, 2013; revised July 22, 2013. This work was supported in part by the Grant-in-Aid for Scientific Research (B, No. 23405049), Japan Society for the Promotion of Science.

Kokyo Oh is with Center for Environmental Science in Saitama, 914 Kamitanadare, kazo, Saitama 347-0115, Japan (e-mail: o.kokyo@pref.saitama.lg.jp).

Tiehua Cao is with Research Center of Agricultural Environment and Resources, Academy of Agricultural Sciences of Jilin Province, China (e-mail: Tiehuacao@163.com).

Tao Li and Hongyan Cheng are with College of Resources and Environment, Shanxi Agricultural University, Shanxi, China (e-mail: ndlitao@126.com, ndchenghy@163.com). expensive than other traditional methods [1], [3], [4].

This paper describes phytoremediation on its characteristics, research status, as well as its practical application on management and remediation of contaminated soils with study cases.

\section{Phytoremediation: Fundamental Processes INVOLVED AND CHARACTESTICS}

Phytoremediation of contaminated soils is generally believed to occur through one or more of the following mechanisms or processes: phytoextraction, phytostabilization, phytodegradation, phytovolatilization, rhizofiltration and rhizodegradation[1], [3], as shown in Fig. 1 and Table I. Phytoremediation is applicable to a broad range of contaminants, including heavy metals and radionuclides, as well as organic compounds like chlorinated solvents, polycyclic aromatic hydrocarbons, pesticides/insecticides, explosives, and surfactants [1], [3].

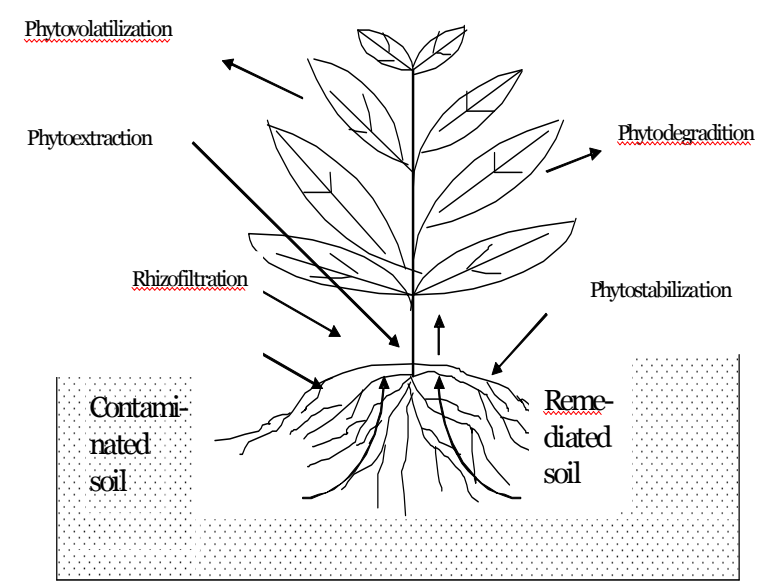

Fig. 1. Phytoremediation processes of contaminated soils

Phytoremediation processes rely on the ability of plants to take up and/or metabolize pollutants to less toxic substances. The uptake, accumulation and degradation of contaminants vary from plant to plant. The plants used in phytoremediation are generally selected on the basis of their growth rate and biomass, their ability to tolerate and accumulate contaminants, the depth of their root zone, and their potential to transpire groundwater [4]. The plants used in phytoremediation should not only accumulate, degrade or volatilize the contaminants, but should also grow quickly in a wild range of different conditions.

As an emerging hopeful technology, phytoremediation for using in management and remediation of contaminated soils has its advantages and limitations. The most positive characteristics are that phytoremediation is a natural and in 
situ remediation system driven by solar and green plants. It is faster than natural attenuation and can conserve the soil resources. It is inexpensive, and does not induce the secondary contamination. Successful phytoremediation can reduce movement of pollutants towards groundwater, sustains the soil structure, and enhance the soil quality and productivity. Soils followed phytoremediation are still or more suitable for its original application particularly for agricultural application, thus preventing the loss of soil resources [1], [3]. Because most of the energy for phytoremediation is supplied by the sun, and phytoremediation does not need to remove the soil out of the place, the costs are very low in comparison to current other physical or chemical methods.

TABLE I: PHYTOREMEDIATION PROCESSES FOR REMEDIATION OF CONTAMINATED SOILS

\begin{tabular}{|c|c|}
\hline $\begin{array}{c}\text { Phytoremediation } \\
\text { processes }\end{array}$ & Description \\
\hline Phytoextraction & $\begin{array}{c}\text { Plants absorb contaminants and store in } \\
\text { above-ground shoots and the harvestable parts of } \\
\text { roots. }\end{array}$ \\
\hline Phytostabilization & $\begin{array}{c}\text { Roots and their exudates immobilize } \\
\text { contaminants through adsorption, } \\
\text { accumulation, precipitation within the root } \\
\text { zone, and thus prevent the spreading of } \\
\text { contaminants. }\end{array}$ \\
\hline Phytodegradation & $\begin{array}{c}\text { Plant enzymatic breakdown of organic } \\
\text { contaminants, both internally and through secreted } \\
\text { enzymes. }\end{array}$ \\
\hline $\begin{array}{c}\text { Rhizodegradation } \\
\text { phytostimulation) }\end{array}$ & $\begin{array}{c}\text { Plant roots stimulate soil microbial communities in } \\
\text { plant root zones to break down contaminants. }\end{array}$ \\
\hline Phytovolatilization & $\begin{array}{c}\text { Contaminants taken up by the roots through the } \\
\text { plants to the leaves and are volatized through } \\
\text { stomata where gas exchange occurs. }\end{array}$ \\
\hline
\end{tabular}

However, as a plant-based remediation, phytoremediation has low remediation rate, and generally need a longer period in comparing with other physicochemical methods. This short coming limits its application particularly in the developed urban areas, where land is extremely expensive. The remediation rate of phytoremediation is different with case by case, as the plant growth was influenced easily by the climate, soil conditions and management practices. Phytoremediation has limited depth. The use of phytoremediation is limited by the climate, soil type, geological conditions of site to be cleaned, and the accessibility for agricultural equipment.

Following critical consideration of these characteristics, phytoremediation can be more suitable for treatment the much larger scale contaminated sites or for treatment of agricultural soils.

\section{RESEARCH StATUS AND ENHANCED METHODS}

The intentional study and development of phytoremediation for metal-contaminated soils was started about 40 years ago, and the phytoremediation for organic pollutants are more recent [3]. Phytoremediation has gained extensively attention and much progress in remediation of inorganic and organic contaminants, and the means for enhanced phytoremediation.
Phytoremediation of various inorganic pollutants such as $\mathrm{Cd}, \mathrm{Cr}, \mathrm{Pb}, \mathrm{Cu}, \mathrm{Zn}, \mathrm{Co}, \mathrm{Ni}, \mathrm{Se}, \mathrm{Cs}$ and $\mathrm{As}$ has been extensively studied. This is mainly based on the use of natural hyperaccumulator plants with exceptional metal-accumulating capacity, which can take up metals to concentrations at least an order of magnitude greater than the normal plants growing in the same environment. These plants have several beneficial characteristics such as the ability to accumulate metals in their shoots and an exceptionally high tolerance to heavy metals [3], [5]. At present, there are totally more than 400 species of hyperaccumulator plants for $\mathrm{As}, \mathrm{Cd}$, $\mathrm{Mn}, \mathrm{Ni}, \mathrm{Zn}$ etc. have been found. For instance, some hyperaccumulator plants and their accumulation concentration $(\mathrm{mg} / \mathrm{kg} \mathrm{dw})$ for various metals are: Thlaspi caerulescens, 51600 for $\mathrm{Zn}$ and 18000 for Cd; Ipomea alpine, 12300 for $\mathrm{Cu}$; Psychotria douarrei, 47500 for $\mathrm{Ni}$; Thlaspi rotundifolium, 8200 for $\mathrm{Pb}$; Astragalus racemosus, 14900 for Se; and Pteris vitatta, 20,000 for As [1], [3].

Plants studied for phytoremediation of various metals, metalloids, non-metals, nutrients, and organic contaminants were reviewed and listed by Pivetz [5], among which Indian mustards, willow, hybrid poplars, duckweed, corn, alfalfa, and ryegrass are very popularly used.

As the most limitation for phytoremediation is the low remediation efficency, the means for enhancing phytoremediation have been extensively studied. Enhanced phytoremediation generally includes the following several ways:

1) Enhanced heavy metal phytoextraction with chemicals: This method is to increases mobility of metals in soil by application of chelating agents or surfactants, such as citric acid, EDTA, CDTA, DTPA, EGTA, EDDHA, and NTA, so that the metals can be taken up more easily by plants [6], [7]. However, some concerns have been expressed regarding the enhanced mobility of metals in soil and their potential risk of leaching to groundwater. Moreover, these soil amendments may also persist in the environment creating additional and unforeseen problems [8].

2) Utilization of Genetically engineered plants: through genetically altering the high biomass plants to extract larger amounts of metal from soils, or improving the biomass production of some hyperaccumulator plants, molecular cloning and expression of heavy metal accumulator genes and xenobiotic degrading enzyme coding genes would resulted in enhanced phytoremediation rates [1], [8]. However, few genetically engineered plants have been used commercially in phytoremediation because of the various safety aspects and regulatory limitation for outdoor use of such plants.

3) Agricultural work techniques: this method is to enhance phytoremediation efficiency by promoting plant growth and microbial activities with suitable fertilization, carbon source addition, or cultivation systems. For example, Huang et al. [9] developed a multi-process, including land farming (aeration and light exposure), microbial inoculation (introduction of contaminant degrading bacteria), and phytoremediation (plant growth), for enhancing the clean-up of persistent organic contaminants from soil. The results showed that this 
method could effectively increase the remediation rate, and possibly shorten more than $50 \%$ of the remediation period.

4) Using plant-microbe combination systems: The rhizosphere is inoculated with new microorganism which is more effective in degrading the contaminant than the local microflora. Good plant-microbe combination can promote the activity of the effective microbes and the plant growth. It is also reported that inoculation of mycorrhizae to some plants may promote the uptake, translocation and accumulation of soil metals [10], [11]. Our research group also established profitable and efficient phytoremediation systems. We use combination systems of biofuel crops such as barley, wheat and corn with white rot fungi for remediation of soil organic contaminants. Results showed that microbial activities (Fig. 2), plant growth as well as the remediation efficiency of dioxins were promoted [12], [13].

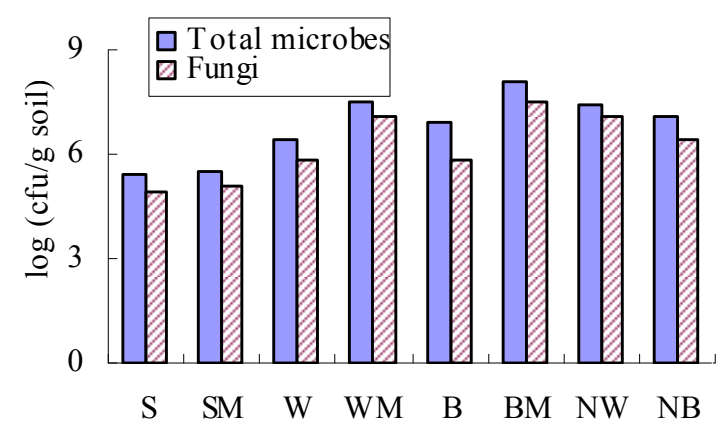

Fig. 2. Soil microbial numbers in various treatments (S: contaminated soil; M: white rot fungi; W: wheat; B: Barley; N: non-contaminated farm soil)

\section{PRACTICAL APpliCATION}

As a promising, not proven, technology, full-scale applications are currently limited to a small number of projects. There have been some project applications in America, Canada and other countries with field-scales since the 1980s, however, only limited information is available about project performance and time frames for project completion [14], [15].

Effective phytoremediation requires firstly making an assessment to the site, correctly selecting plant species, and implementing a suitable plant or crop management regime. Soil amendments may need to be added to enhance plant growth and/or contaminant uptake or degradation.

The following are several cases related to the primary application of phytoremediation for environmental cleanup.

\section{A. Phytoremediation of Metal-Mined Soils}

Mining activities generated a large amount of waste rocks and tailings, which results in loss of cultivated land, forest or grazing land, and induce heavy metal pollution of soils. The practice is to choose appropriate plant species, which can grow quickly in the metal-contaminated and nutrient deficient soils, to establish a self-sustainable vegetation cover. This practice can reduce metal mobility and bioavailability for entry into the food chain and underground water, and can get the benefit on pollution control, stabilization, visual improvement and removal of threats to human beings.

Many plant cultivars tolerant to toxic metals, such as Cynodon dactylon, Vetiveria zizanioides, Festuca rubra and Typha latifolia [16]. Some of the metal-tolerant plants are available commercially in some countries. For instance, vetiver grass ( $V$. Zizanioides) was successfully demonstrated as a fine plants in protection $\mathrm{Pb} / \mathrm{Zn}$ mine spoils in China [16], [17]. Vetiver grass has a massive finely structured and deep root system, and it is well known for its effectiveness in soil erosion control. Vetiver grass has been found to be highly tolerant to drought, flood, submergence, extreme temperature, a wide range of soil $\mathrm{pH}$, and toxicities of various heavy metals. The study showed that vetiver grass produced the highest biomass production and coverage compared with other three plants when used for revegetating $\mathrm{Pb} / \mathrm{Zn}$ mine tailings in South China. By planting vetiver grass in the meal-contaminated soils, it reached the purpose of controlling erosion and leaching on metalliferous mine tailings, improving soil fertilities, enhancing public appeal, and at the same time producing oils with a high commercial value [16].

\section{B. Phytoremediation of Soil Cd Contamination in Japan}

Arable land in Japan, especially paddy fields, is contaminated to some extent by $\mathrm{Cd}$ through irrigation with river water from mines or through emission from metal-smelters, which have caused some serious problems, especially in 1970s. It is urgent to reduce the $\mathrm{Cd}$ concentration of rice. In recent years, phytoremediation was tried as a promising approach for reducing $\mathrm{Cd}$ in soils. Some indica-japonica cross varieties with high ability of $\mathrm{Cd}$ accumulation under upland cultivation were found. The concentration in the varieties is 2 to 4 times of a hyperaccumulator, B. juncea. Moreoever, Cd uptake in the shoots of the rice was about 6 times of the B. juncea. A remarkable decrease in $\mathrm{Cd}$ content in the rhizosphere was found after harvesting the rice. According to the results of pot experiment, by using Milyang 23, one of the high $\mathrm{Cd}$-accumulating rice varieties with a high yielding biomass. It is estimated that remediation of a low-level $\mathrm{Cd}$ contaminated soil with $0.7 \mathrm{mg} \mathrm{kg}-1$ of $0.1 \mathrm{M} \mathrm{HCl}$ extractable $\mathrm{Cd}$, can be finished within 3 to 4 years. A high removal efficiency of Cd by Milyang 23 was also confirmed by a field experiment, in which about $190 \mathrm{~g}$ ha- 1 of $\mathrm{Cd}$ was removed from a paddy field polluted with $2.5 \mathrm{mg} \mathrm{kg}^{-1}$ of Cd. It showed this way is very suitable for remediate the $\mathrm{Cd}$ contaminated fields in Japan [18], [19]. At present, the processes of this technology including the rice planting and management, harvest, transportation, incineration, and recovery of $\mathrm{Cd}$ from the ash are under developing.

\section{Phytoremediation of Born (B) in a Sawdust Pile in New Zealand}

Phytoremediation have conducted for solving the B contamination from a sawdust pile in New Zealand [15]. The pile has a surface of 3.6 ha and an average depth of $15 \mathrm{~m}$. Over a 30-year period, from 1966, sawdust and yard-scrapings from timber milling in the region were dumped on the pile. Land around the pile has been engineered so that no surface or ground water enters the pile, and all leachate resulting from rainfall is collected in a small holding pond at the foot of the pile. The overflow from the holding 
pond enters a local stream. The overflow often increased B concentration in the stream to a level over $1.4 \mathrm{mg} / \mathrm{L}$, the New Zealand Drinking Water Standard (NZDWS). In response to these breaches, the local environmental authority used the phytoremediation technology for remediation of the site. A 1-ha trial was established with several kinds of plants, and at last two populous deltoids hybrid clones were then selected as the best candidates for phytoremediation based on survival, biomass production, and $\mathrm{B}$ uptake ability. The following year, the remainder of the pile was planted to these 2 clones at a density of 7000 trees/ha. As a result, the phytoremediation makes the bare site become a growing green plant landscape. The above-ground biomass production in the first and second years was about 1.2 and 13.3 ton ha $^{-1}$ dry matter, respectively. At the end of the growing season, the average leaf $\mathrm{B}$ concentration was nearly $700 \mathrm{mg} / \mathrm{kg}$ dry matter, over 28 times higher than the $\mathrm{B}$ concentration in the sawdust. The fallen leaves with high B content were used as an organic B supplement to trees in the orchards that are B-deficient in other places. The concentrations of other heavy metals in the leaves are unlikely to cause further environmental problems. The B concentration in the drainage water decreased progressively during the experiment, and after 2 years, the $\mathrm{B}$ concentration dropped below the NZDWS (1.4 mg/L). The total cost of this phytoremediation is estimated to be NZ\$ 200,000, including site assessment, chemical analysis, and a 5-year site maintenance plan, while the alternative cost of capping the site was estimated to be over NZ\$1.2 million [8].

\section{Phytoremediation of Contaminated Aricultural Soils with Biofuel Crops}

To promote the practical application of phytoremediation for contaminated soil, we are carrying studies of phytoremediation with biofuel crops. As biofuel crops can be used for soil remediation and biofuel production, they can bring income to the owners of contaminated sites, thus the practical application of phytoremediation can be promoted and the soil resources can be protected. Our final objective is to develop a profitable phytoremediation system, in which the owners of the contaminated sites can obtain income as they conduct phytoremediation. Here we give a brief introduction of our primary study. In this study, some crop-microbe systems were primarily developed, and the effects on plant biomass, soil microbes, and remediation efficiency were assessed.

\section{1)Materials and methods}

Wheat (Triticum spp.) and barley (Hordeum vulgare L.) were grown in pots filled with a dioxins-contaminated soil or with a natural arable soil. The microbe was used is Hiratake (Pleurotus ostreatus), a white-rot-fungus with high health safety and high degradation potential to organic contaminants. The pots were put in the field of the Center for Environmental Science in Saitama. The crop seedlings were then given the following treatment 30 days after emergence 1) non-inoculation, and 2) inoculation with Hiratake, with control treatments of non-vegetated pots. No microbe inoculation made to the natural arable soil. Three replicates of each treatment were removed when harvested for soil and plant analysis. The measured items including total biomass of the crops and ear yield of the crops, number of total soil microorganisms and fungi, and soil dioxins concentrations.

\section{2) Results and discussion}

Increase in the total biomass of the wheat and barley, and their ear yields were found in treatments with Hiratake compared with that without inoculation (Fig. 3). However, biomass and ear yields were much lower than that of the natural arable soil. This indicates that the contaminated soil had worse condition for plant growth than arable soil, but Hiratake inoculation can promote crop growth in the contaminated soil.

As shown in Fig. 4, nearly no differences were found in dioxins concentration among the treatment without crop plantation. The treatments with only wheat or barley had slight decrease in dioxins concentration, but wheat or barley plantation with Hiratake inoculation had larger decrease. Compared with the original soil, barley with Hiratake (BM) had a $35 \%$ decrease in soil dioxins, while wheat with Hiratake (WM) had a $24 \%$ decrease.
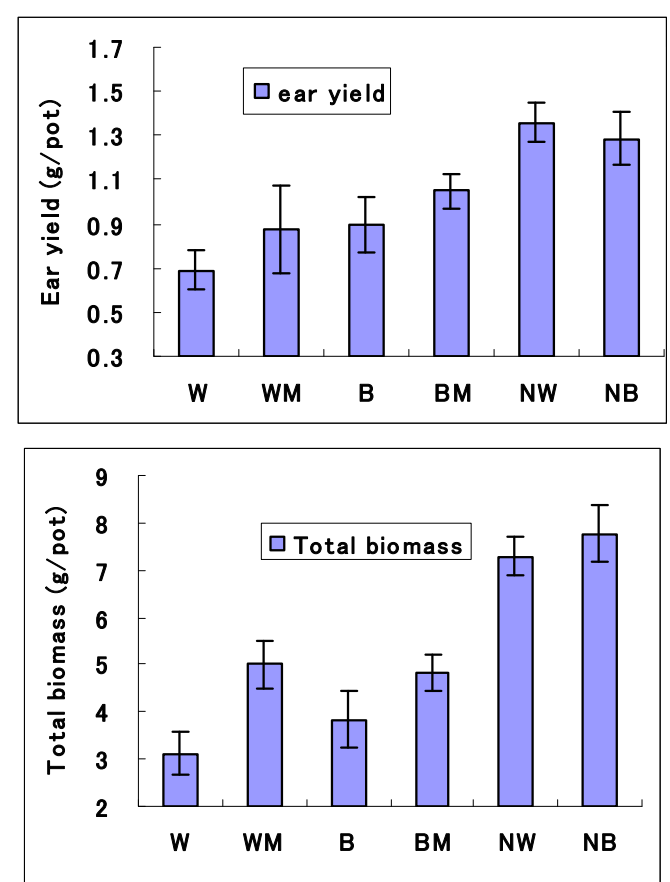

Fig. 3. Biomass in treatments with or without Hiratake inoculation [13] (W: wheat; B: Barley; M: Hiratake; N: natural arable soil)

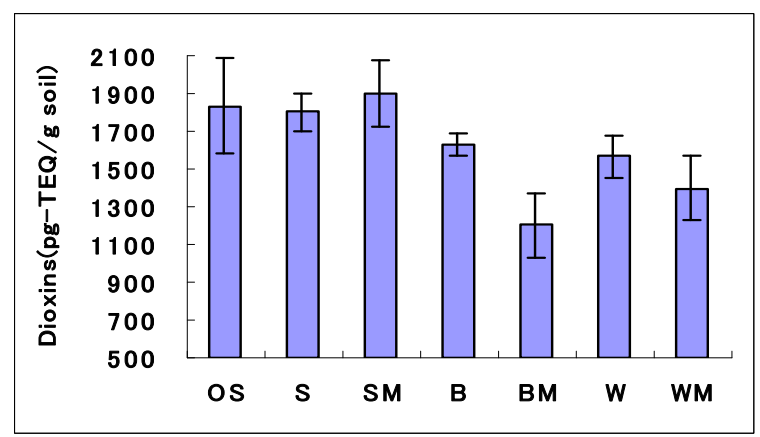

Fig. 4. Changes in dioxins concentration [13]

(OS: original soil; W: wheat; B: Barley; M: Hiratake; N: natural arable soil)

In summary, wheat and barley with Hiratake inoculation greatly promoted crop biomass and ear yields, soil microbial population, and dioxins removal efficiency, suggesting that crop-Hiratake system is possibly a choice for enhancing phytoremediation. 


\section{CONCLUSION}

Phytoremediation of contaminated sites supports the goal of sustainable development by helping to conserve soil as a resource, bring soil back into beneficial use, preventing the spread of pollution to air and water, and reducing the pressure for development on green or agricultural field sites. Phytoremediation offers the possibility of a cost effective remediation means for a wide range of contaminated sites. It will be most applicable to soil contaminations that not so deep from soil surface, relatively non-leachable, and cover a large area.

So far, the processes by which of phytoremediation systems accumulate and degrade contaminants are still poorly understood. Further effects for increasing the scope and efficiency of phytoremediation, and for developing phytoremediation systems for sites contaminated with multi-contaminants are urgently necessary. Although some companies have started their business in phytoremediation, phytoremediation has not been fully commercialized. Further research is still needed, and the priorities on phytoremediation for the future should focus on establishing stable and efficient phytoremediation systems through finding more efficient remediation plants and microbes, monitoring current field trials to obtain thorough understanding, developing microbe-plant combination systems, and using genetic engineering technology.

As phytoremediation need a long period, it has not been fully utilized. Further promotion to the practical application of phytoremediation to removal of contaminated soil needs to establish more effective ways for profitable phytoremediation systems. The use of economic plants such as biofuel crops for utilization and remediation of the contaminated sites would be a reasonable choice, as they can both remediate contaminated soils and produce valuable biomass, which could bring income for the owner of the contaminated site.

Phytoremediation are expected to be used as a vital tool in sustainable management of contaminated soils. Contaminated site managers should consider phytoremediation when evaluating remedial alternatives.

\section{REFERENCES}

[1] K. Oh, T. Li, H. Y. Cheng, Y. Xie, and S. Yonemochi., "Development of Profitable Phytoremediation of Contaminated Soils with Biofuel Crops," Journal of Environmental Protection, vol. 4, pp. 58-64, 2013.

[2] F. Li, Z. Fan, P. Xiao, K. Oh, X. Ma, and W. Hou, "Contamination, chemical speciation and vertical distribution of heavy metals in soils of an old and large industrial zone in Northeast China," Environ. Geol. vol. 57, pp. 1815-1823, 2009.

[3] X. J. Wang, F. Y. Li, M. Okazaki, and M. Sugisaki, "Phytoremediation of contaminated soil", Annual Report CESS, vol. 3, pp. 114-123, 2003.

[4] K. Oh, T. Li, H. Cheng, X. Hu, Q. Lin, and Y. Xie, "A Primary Study on Assessment of Phytoremediation Potential of Biofuel Crops in Heavy Metal Contaminated soil," Applied Mechanics and Materials, vols. 295-298, pp. 1135-1138, 2013.

[5] P. Ahmadpour, F. Ahmadpour, T. M. M. Mahmud, Arifin Abdu, M. Soleimani and F. H. Tayefeh, "Phytoremedia- tion of Heavy Metals: A Green Technology," African Jour nal of Biotechnology, vol. 11, No. 76, pp. 14036- 14043, 2012.

[6] B. E. Pivetz, Phytoremeidation of contaminated soil and ground water at hazardous waste sites, EPA/540/S-01/500, pp. 36, 2001.
[7] E. M. Cooper and J. T. Sims, "Chelate-assisted phytoextraction of lead from contaminated soils,” J. Environ. Qual., vol. 28, pp. 1709-1719, 1999.

[8] B. Robinson, S. Green, T. Mills, B. Clothier, M. van der Velde, R. Laplane et al., "Phytoremediation: using plants as biopumps to improve degraded environments," Aust. J. Soil Res., vol 41, pp. 599-611, 2004.

[9] X. D. Huang, Y. El-Alawi, J. Gurska, B. R. Glick, and B. M. Greenberg, "A multi-process phytoremediation system for decontamination of persistent total petroleum hydrocarbons (TPHs) from soils," Microchemical J. , vol. 81,pp. 139-147, 2005.

[10] A. G. Khan, C. Kuek, T. M. Chaudhry, C. S. Khoo, and W. J. Hayes, "Role of plants, mycorrhizae and phytochelators in heavy metal contaminated land remediation," Chemosphere, vol. 41, pp. 197-207.

[11] X. Chen, C. Wu a, J. Tang a, and S.Hu,"Arbuscular mycorrhizae enhance metal lead uptake and growth of host plants under a sand culture experiment," Chemosphere, vol. 60, pp. 665-671, 2005.

[12] K. Oh., M. Sugisaki, S. Hosono, F. Li, and T. Hirano, "Study on remediation of dioxin-contaminated soil by plant-microbial combinations," Organohalogen Compounds, vol 69, pp. 2536-2539, 2005.

[13] K. Oh, S. Hosono, Q. Lin, Y.H. Xie, F.Y. Li, C.J. Jiang, and T. Hirano, "Remediation of Dioxin-contaminated Soil with Combination of Biofuel crops and white rot fungus," Organohalogen Compounds, vol. 71, pp. 1177-1182, 2009

[14] EPA, "Use of Field-Scale Phytotechnology for Chlorinated Solvents, Metals, Explosives and Propellants, and Pesticides," EPA 542-R-05-002, pp. 1-14, 2005.

[15] P. Ji, T. Sun, Y. Song, M. Leigh Ackland, and Y. Liu, "Strategies for enhancing the phytoremediation of cadmium-contaminated agricultural soils by Solanum nigrum L," Environmental Pollution, vol. 159, pp. 762-768, 2011.

[16] M. H. Wong, "Ecological restoration of mine degradation soils, with emphasis on metal contaminated soils," Chemosphere, vol. 50, pp. 775-780, 2003.

[17] W. S. Shu, "Use of vetiver and other three grasses for revegetation of $\mathrm{Pb} / \mathrm{Zn}$ mine Tailings at Lechang, Guangdong Province: field experiment", in Proc. 2nd Int. Vetiver Conf., Bangkok, Thailand, 2000.

[18] T. Arao and N. Ae, "Genotypic variations in cadmium levels of rice grain”, Soil Sci. Plant Nutr., vol. 49, pp. 473-479, 2003.

[19] S. Ishikawa, "Promising technology for reducing cadmium contamination in rice," Rice is life: Scientific Perspectives for the 21st Century, in Toriyama et al. eds. pp. 381-384, 2005.

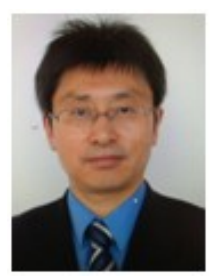

Kokyo Oh is a senior researcher in Center for Environmental Science in Saitama, Japan. He graduated with his MSci degree and Ph.D. degree in Chinese Academy of Sciences, and was honored as a STA research fellow by Japan government. The research areas include soil environment, water environment conservation environmental chemistry, and atmospheric environment. His current research is mainly on soil remediation, environmental agronomy, atmospheric environment and water environment conservation. He has published more than 90 publications.

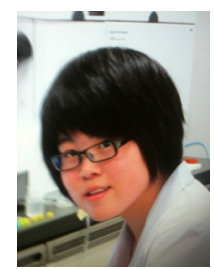

Tao $\mathbf{~ L i ~ i s ~ a ~ m a s t e r ~ c o u r s e ~ s t u d e n t ~ o f ~ S h a n x i ~ A g r i c u l t u r a l ~}$ University (China). She is studying and doing research assistant on environmental science. She has been invited to do international cooperation research in Japan for two times as she is an excellent student with very cooperative personal character as well as active and hardworking spirit.

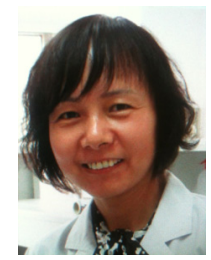

Hongyan Cheng is a professor of Shanxi Agricultural University (China). Her current research interest is on soil environment, phytoremediation, and chemical analysis. She has published more than 30 publications, and actively cooperated with overseas research institutions. 